\title{
Nuclear and nucleolar image analysis of human breast epithelial cells transformed by benzo[a]pyrene and transfected with the c-Ha-ras oncogene
}

\author{
Luís Fernando Barbisan ${ }^{\mathrm{a}}$, Jose Russo ${ }^{\mathrm{b}}$ and Maria Luiza S. Mello ${ }^{\mathrm{a}, *}$ \\ ${ }^{a}$ Department of Cell Biology, Institute of Biology, UNICAMP, 13083-970, Campinas, SP, Brazil \\ ${ }^{\mathrm{b}}$ Breast Cancer Research Laboratory, Fox Chase Cancer Center, Philadelphia, PA 19111, USA
}

Received 8 October 1997

Revised 6 February 1998

Accepted 26 February 1998

\begin{abstract}
Changes in nuclear and nucleolar morphometric parameters were investigated by image analysis procedures in human breast MCF-10F epithelial cells expressing different stages of the tumourigenic progression after benzo[a]pyrene (BP) transformation (BP1, BP1-E, and BP1-E1 cell lines), and additionally transfected with the c-Ha-ras oncogene (BP1Tras cell line). Nuclear pleomorphism was evident in all the transformed cells. The analysis of different morphometric parameters did not show a clear relationship between specific nuclear and nucleolar changes and the expression of the different stages of the tumourigenesis, with the exception of the nucleolar size, which could be associated to the expression of the tumourigenic phenotype, and a nucleolar area/nuclear area ratio, which discriminated the immortalized, the transformed, and the tumourigenic phenotypes from one another. The nuclear morphometric data established for the BP-transformed cells and for the cells additionally transfected with the c-Ha-ras oncogene were suggestive of complex and distinct morphofunctional mechanisms involving the in vitro transformation of the MCF-10F cells. The nuclear changes found in the BP1-Tras cell line were assumed to be related to the additional effects and/or enhanced genomic instability induced by transfection with the ras oncogene.
\end{abstract}

Keywords: Human breast epithelial cells, benzo[a]pyrene, c-Ha-ras oncogene, image analysis, nuclear/nucleolar morphometry

\section{Introduction}

Neoplastic transformation is a multistep process that leads cells to morphological and physiological progressive changes due to the inactivation of tumour suppressor genes and the activation of oncogenes that act at different cellular sites $[7,18]$. In particular, the activation of oncogenes that act on the nuclear matrix and DNA, leading to changes in nuclear shape and function (e.g., structural and DNA instability), has been seen as a common event in the tumourigenic process [18]. Alterations in nuclear

\footnotetext{
${ }^{*}$ Corresponding author. Fax: +5519 2893124/7887821.
} 
size, shape and chromatin texture have been demonstrated during in vitro neoplastic transformation induced by chemical carcinogens and c-Ha-ras oncogene transfection in murine and human cells [13, $14,16]$.

Spontaneously immortalized human breast epithelial cell lines, MCF-10A and F, have been used as experimental models to study the in vitro neoplastic progression induced by chemical carcinogens and/or c-Ha-ras transfection [2,4,5,21]. MCF-10F cells have been successfully transformed in vitro by exposure to the chemical carcinogen benzo[a]pyrene (BP) [4]. BP-exposed cells gave rise to BP1 and BP1-E cell lines that show higher proliferative rates, increased anchorage-independent growth and in vitro chemotactic and chemoinvasive abilities. The BP1-E cell line, but not the parental cell line, expresses the tumourigenic phenotype in severe combined immunodeficient (SCID) mice [4].

The c-Ha-ras oncogene has apparently been involved in both early and late stages of the tumourigenic process in spontaneously immortalized human breast epithelial MCF-10A and MCF-10F cell lines [2,5]. The insertion of the c-Ha-ras oncogene in transformed BP1 cells, originating the BP1-Tras cell line, was proven to be sufficient to enhance the neoplastic changes initiated by exposure to BP, including the expression of the tumourigenic phenotype in SCID mice [5]. Thus, cell lines expressing different stages of the tumourigenic progression induced by BP exposure and c-Ha-ras transfection would certainly provide some cytodiagnostic advantages for studying the relationship between the expression of different nuclear phenotypes and the in vitro malignant transformation.

Here we investigated by image analysis procedures nuclear and nucleolar morphometric changes in human breast epithelial cell lines transformed by benzo[a]pyrene and additionally transfected with the c-Ha-ras oncogene.

\section{Materials and methods}

\subsection{Cell lines and culture conditions}

Nontransformed (MCF-10F) and benzo[a]pyrene-transformed (BP1, BP1-E and BP1-E1) cells were used. The BP1-Tras line, obtained by transfection of BP1 cells with the c-Ha-ras oncogene [5], was also studied. The cells were grown in Dulbecco's minimal essential medium/F-12 medium (1:1) supplemented with $5 \%$ equine serum, $0.1 \mu \mathrm{g} / \mathrm{ml}$ cholera-toxin, $10 \mu \mathrm{g} / \mathrm{ml}$ insulin, 100 units $/ \mathrm{ml}$ penicillin, $100 \mu \mathrm{g} / \mathrm{ml}$ streptomycin, $2.5 \mu \mathrm{g} / \mathrm{ml}$ amphotericin B (Gibco, Grand Island, NY, USA), $0.5 \mu \mathrm{g} / \mathrm{ml}$ hydrocortisone (Sigma) and $0.02 \mu \mathrm{g} / \mathrm{ml}$ epidermal growth factor (Collaborative Research Inc., Palo Alto, CA, USA), as described previously [21].

\subsection{Cell preparations and staining}

The cells grown on coverslips were fixed in an absolute ethanol-acetic acid mixture $(3: 1, \mathrm{v} / \mathrm{v})$ for $1 \mathrm{~min}$, rinsed in $70 \%$ ethanol for 3-5 min and air-dried. Staining was carried out with a $0.025 \%$ toluidine blue (Merck) solution in McIlvaine buffer at $\mathrm{pH} 4.1$ for 15 min. Immediately after staining, the preparations were treated with a $0.05 \mathrm{M}$ aqueous $\mathrm{MgCl}_{2}$ solution for $15 \mathrm{~min}$, rapidly rinsed in distilled water, air-dried overnight, cleared in xylene and mounted in Canada balsam. This cytochemical procedure has been proposed for visualization of the nucleolus and RNA relocation during cell division $[12,15]$. 


\subsection{Image analysis}

Nuclear and nucleolar morphometric parameters were evaluated by image analysis procedures in a Luzex-F-Nireko-Japan Image Analysis System. Nuclear and nucleolar area, perimeter and form factor (defined as perimeter ${ }^{2} /(4 \pi \times$ area $\left.) \times 100\right)$ were assessed at a $1000 \times$ magnification for micrograph film negatives of 100 cells of each cell line. The micrographs were obtained in a Zeiss photomicroscope. The film negatives were analyzed in the Luzex system through a special Macro-Stand device adequate for that. The image input was made through a Canon TV zoom lens V6 $\times 16 / 16-100 \mathrm{~mm}$ plus a Canon $58 \mathrm{~mm}$ close-up 240 lens connected to a CCD black-and-white video camera module with a Sony DC-777 camera adaptor unit. Calibration was carried out before each measurement session using the negative of a millimetric ruler as standard and setting up a pixel size for each adjustment condition. Processing, binarization and measurement of these images (defined in terms of grey values) were made by a Luzex F standard program. The images were digitized by an A/D conversor into 8 bit digital images. Segmentation was performed by setting an automatic threshold level or interactively, by manual tracing, when necessary.

A nucleolar/nuclear area ratio (defined as the ratio between the measured nucleolar and nuclear areas) and the nucleolus number per nucleus were also calculated.

The shape factor equals 100 when the nuclear or the nucleolar outlines are regular circles and becomes higher than 100 when these structures have an irregular shape.

\subsection{Statistical analysis}

A descriptive analysis for the morphometric data was carried out. Multiple comparisons among the different parameters were then performed using the nonparametric Kruskal-Wallis test $(\alpha=$ $0.05 \%)[11]$.

\section{Results}

Well contrasting nucleolar images were obtained, favouring their quantitative analysis (Fig. 1).

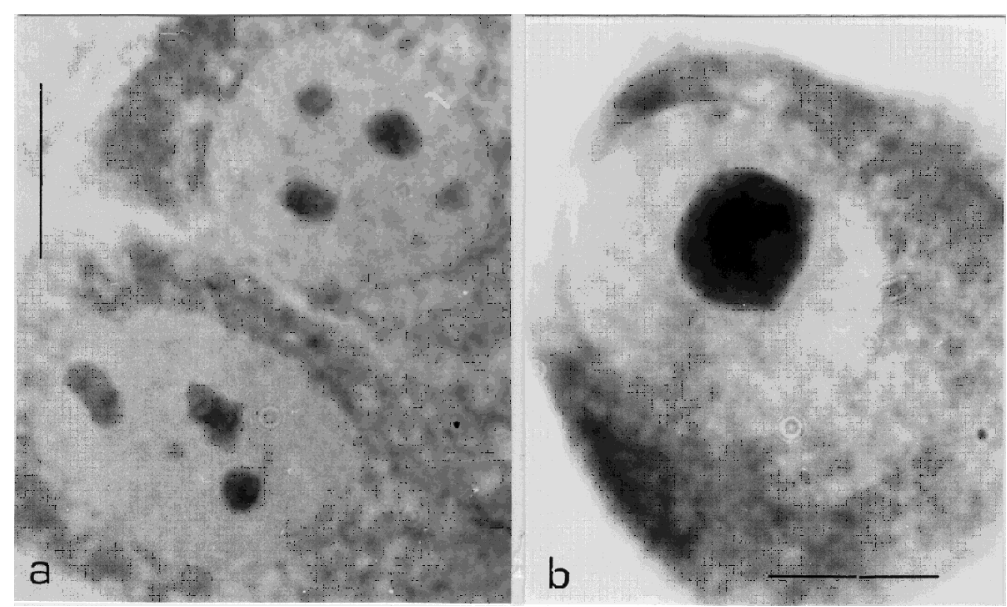

Fig. 1. Cells exhibiting well discriminated nucleoli in preparations stained according to Mello et al.'s [15] procedure. A situation of extreme contrast as regards number and size of nucleoli was purposedly chosen. (a) MCF-10F control cell; (b) BP1-Tras cell. Bar $=10 \mu \mathrm{m}$. 
Table 1

Nuclear parameters in human breast epithelial cells transformed by benzo[a]pyrene and transfected with the c-Ha-ras oncogene $(n=100)$

\begin{tabular}{|c|c|c|c|c|c|c|c|c|}
\hline \multirow[t]{2}{*}{ Cells } & \multicolumn{2}{|c|}{$\begin{array}{l}\text { Nuclear area } \\
\qquad\left(\mu \mathrm{m}^{2}\right)\end{array}$} & \multicolumn{2}{|c|}{$\begin{array}{l}\text { Nucleolar area } \\
\left(\mu \mathrm{m}^{2}\right)\end{array}$} & \multicolumn{2}{|c|}{$\begin{array}{l}\text { Nucleolar area/ } \\
\text { nuclear area }\end{array}$} & \multicolumn{2}{|c|}{$\begin{array}{c}\text { Nuclear perimeter } \\
(\mu \mathrm{m})\end{array}$} \\
\hline & $\overline{\bar{X}}$ & $S$ & $\bar{X}$ & $S$ & $\overline{\bar{X}}$ & $S$ & $\overline{\bar{X}}$ & $S$ \\
\hline MCF-10F & 134.97 & 34.13 & 11.73 & 3.25 & 0.09 & 0.02 & 44.96 & 7.58 \\
\hline BP1 & 111.32 & 30.56 & 12.50 & 3.49 & 0.11 & 0.03 & 40.44 & 7.77 \\
\hline BP1-E & 124.42 & 36.47 & 18.29 & 6.36 & 0.15 & 0.04 & 42.21 & 5.81 \\
\hline BP1-E1 & 123.15 & 31.59 & 16.15 & 4.46 & 0.14 & 0.03 & 42.17 & 5.46 \\
\hline BP1-Tras & 144.71 & 56.41 & 24.92 & 8.44 & 0.18 & 0.03 & 44.39 & 8.15 \\
\hline \multirow[t]{2}{*}{ Cells } & \multicolumn{2}{|c|}{$\begin{array}{l}\text { Nuclear form } \\
\text { factor }\end{array}$} & \multicolumn{2}{|c|}{$\begin{array}{l}\text { Nucleolar perimeter } \\
\qquad(\mu \mathrm{m})\end{array}$} & \multicolumn{2}{|c|}{$\begin{array}{l}\text { Nucleolar form } \\
\text { factor }\end{array}$} & \multicolumn{2}{|c|}{$\begin{array}{l}\text { No. of nucleoli/ } \\
\text { nucleus }\end{array}$} \\
\hline & $\overline{\bar{X}}$ & $S$ & $\overline{\bar{X}}$ & $S$ & $\bar{X}$ & $S$ & $\overline{\bar{X}}$ & $S$ \\
\hline MCF-10F & 114.66 & 4.31 & 23.61 & 6.58 & 159.27 & 51.86 & 2.7 & 1.1 \\
\hline BP1 & 117.61 & 6.51 & 23.55 & 6.73 & 137.38 & 32.88 & 2.7 & 1.2 \\
\hline BP1-E & 116.30 & 4.88 & 27.47 & 9.48 & 171.55 & 58.08 & 2.3 & 1.2 \\
\hline BP1-E1 & 116.18 & 5.68 & 27.26 & 5.72 & 142.02 & 24.45 & 2.5 & 0.9 \\
\hline BP1-Tras & 113.25 & 4.25 & 23.84 & 6.64 & 127.29 & 16.73 & 1.5 & 0.7 \\
\hline
\end{tabular}

$\bar{X}$, arithmetic mean; $S$, standard deviation.

Table 2

Kruskal-Wallis' test comparisons

\begin{tabular}{lcccccccc}
\hline Cells & $\begin{array}{c}\text { Nuclear } \\
\text { area }\end{array}$ & $\begin{array}{c}\text { Nucleolar } \\
\text { area }\end{array}$ & $\begin{array}{c}\text { Nucleolar } \\
\text { area/nuclear } \\
\text { area }\end{array}$ & $\begin{array}{c}\text { Nuclear } \\
\text { perimeter }\end{array}$ & $\begin{array}{c}\text { Nuclear } \\
\text { form factor }\end{array}$ & $\begin{array}{c}\text { Nucleolar } \\
\text { perimeter }\end{array}$ & $\begin{array}{c}\text { Nucleolar } \\
\text { form factor }\end{array}$ & $\begin{array}{c}\text { No. of } \\
\text { nucleoli/ } \\
\text { nucleus }\end{array}$ \\
\hline MCF-10F & $\mathrm{A}$ & $\mathrm{A}$ & $\mathrm{A}$ & $\mathrm{A}$ & $\mathrm{A}$ & $\mathrm{A}$ & $\mathrm{A}$ & $\mathrm{A}$ \\
$\mathrm{BP1}$ & $\mathrm{C}$ & $\mathrm{A}$ & $\mathrm{B}$ & $\mathrm{C}$ & $\mathrm{BC}$ & $\mathrm{A}$ & $\mathrm{B}$ & $\mathrm{A}$ \\
$\mathrm{BP1}-\mathrm{E}$ & $\mathrm{B}$ & $\mathrm{B}$ & $\mathrm{C}$ & $\mathrm{B}$ & $\mathrm{AC}$ & $\mathrm{AB}$ & $\mathrm{AC}$ & $\mathrm{B}$ \\
BP1-E1 & $\mathrm{B}$ & $\mathrm{B}$ & $\mathrm{D}$ & $\mathrm{B}$ & $\mathrm{AC}$ & $\mathrm{B}$ & $\mathrm{A}$ & $\mathrm{AB}$ \\
BP1-Tras & $\mathrm{AB}$ & $\mathrm{C}$ & $\mathrm{E}$ & $\mathrm{AB}$ & $\mathrm{B}$ & $\mathrm{A}$ & $\mathrm{B}$ & $\mathrm{C}$ \\
\hline
\end{tabular}

Different cell lines showing the same letter for a certain parameter indicate that their median ranks do not differ at $p<0.05$; different letters for different cell lines, on the other hand, indicate differences significant at $p<0.05$.

Table 1 shows the morphometric data obtained for the different cell lines. Since these data did not always give a normal distribution, they were compared using the nonparametric Kruskal-Wallis test (Table 2).

Nuclear pleomorphism was detected in all the BP-transformed cell lines. Nuclei with smaller areas and perimeters but with more irregular shapes were found in BP1, BP1-E and BP1-E1 cell lines in comparison with the nontransformed cells. The nuclear area and perimeters of the BP1-Tras cells were found not to differ from those of the nontransformed MCF-10F and the tumourigenic BP1-E and BP1-E1 cells (Tables 1 and 2).

Nucleolar enlargement was characteristic of the cells that express the tumourigenic phenotype, especially in the BP1-Tras cell line (Tables 1 and 2). Higher values for nucleolar area and perimeter were more frequent in the tumourigenic BP1-E and BP1-E1 cell lines. On the other hand, nucleoli with lower perimeter values and more regular shapes were very common in BP1 and BP1-Tras cells (Tables 1 and 2). The number of nucleoli per nucleus in BP1-E and BP1-Tras cell lines was found 
to differ from that detected in BP1 and BP1-E1 transformed cells and in nontransformed MCF-10F cells. As regards the nucleolar area/nuclear area ratio, there was discrimination of the immortalized, the transformed and the tumourigenic phenotypes (Table 2).

A relationship between increased nucleolar sizes and decreased nucleolus number was especially evident in the tumourigenic BP1-Tras cells (Table 1).

\section{Discussion}

Changes in nuclear and nucleolar morphometric parameters have been proposed by several authors as tools for breast cancer diagnosis, grading and prognosis [8,22-24]. The present results suggest that certain nuclear and nucleolar morphometric changes evaluated by image analysis can be associated to the in vitro neoplastic progression in MCF-10F cells. Nuclear pleomorphism, a cellular characteristic observed during malignant progression of primary human breast cancer [22,23], was a very common feature in the BP-transformed MCF-10F cells.

The alterations in nuclear morphometry quantified in the BP-transformed MCF-10F cell lines may be due to changes in their DNA amounts and/or chromatin packing states. In fact, a decreased DNA content and an increased chromatin supra-organizational packing state have been found by video and microspectrophotometric image analysis in tumourigenic BP1-E1 cells as compared to the nontransformed control [25].

The especially high variability in nuclear area and perimeter values in cells of the BP1-Tras cell line may, in part, be associated to a higher Feulgen-DNA content variability induced by the transfected c-Ha-ras oncogene and involving the presence of aneuploid, diploid and polyploid nuclei [17]. However, polyploidy is not assumed to be the unique factor responsible for differences in the nuclear/nucleolar parameters as regards comparison of BP1-Tras $\times$ BP1 cells or BP1-Tras $\times$ BP1-E1 cells, especially considering that the nucleolar area/nuclear area ratio of these cells siginificantly differ from each other. In addition to the transforming potential of the activated c-Ha-ras oncogene, experimental evidence shows that the insertion of this oncogene induces genomic instability in transfected cells $[6,9,26]$. The exposure of MCF-10F cells to benzo[a]pyrene has proven to result in loss of one of the alleles of the c-Ha-ras oncogene and point mutation in codons 12 and 61 of the remaining allele [28]. Transfection of the human T24 mutated c-Ha-ras oncogene to transformed BP1 cells has induced additional effects on the expression of tumourigenesis in these cells, originating in the highly tumourigenic BP1-Tras cell line, and indicating that the c-Ha-ras oncogene can be involved in the early and late steps of the in vitro tumour progression [5].

The decrease in nucleolus number (probably by a mechanism eliciting nucleolus fusion) in BP1-E and BP1-Tras cell lines, and the nucleolar enlargement in nuclei of the BP1-E, BP1-E1, and BP1-Tras tumourigenic cell lines possibly reflect their enhanced metabolic activities as compared with the other cell lines. In cells with increasing demand for a rapid supply of ribosomes it has been reported that NORs may move within the nucleus, coming to a single zone and leading to fusion of nucleoli [20]. In general, metabolically active and proliferating cells have abundant and/or greater nucleoli [10]. Particularly in the case of the breast cancer, an increase in number and/or size of the nucleoli has been associated to a higher grading and a poorer prognosis [22,23].

As regards changes in nuclear shape, it should be considered that the ras proto-oncogene is affected in the BP-transformed cells studied here [28], and that proteins of the ras superfamily have been reported to be involved in regulation of the actin polymerization spatial pattern [3,19]. Since there is a close interaction between cytoplasmic and nuclear cytoskeletons, the irregularly shaped nuclei observed 
in the BP-transformed cell lines may result from altered actin organization/assembly, leading to changes in cell morphology and cellular motility. In support of this idea is the fact that the BP-transformed MCF-10F cells have shown increased in vitro chemotactic and chemo-invasive abilities [4].

Among the morphometric parameters studied in this investigation, the nucleolar area could be associated with the expression of the tumourigenic phenotype. Furthermore, when the nucleolar area was associated to the nuclear area in the form of another descriptor (nucleolar area/nuclear area ratio), this one was sensitive enough to distinguish the immortalized (MCF-10F), the transformed (BP1) and the various tumourigenic phenotypes from one another. These parameters thus reveal progressive morphological changes in the transformed MCF-10F cell lines as a function of accumulated genomic alterations which are characteristic of the multistep process involved [1,4-6,27,29].

\section{Acknowledgements}

This investigation was supported by the São Paulo State Research Foundation (FAPESP, grant no. 95/6629-8) and by NCI grant PHS-CA67238. LFB and MLSM were the recipients of fellowships from the Brazilian R\&D National Council (CNPq).

\section{References}

[1] N. Barnabas, R. Moraes, G. Calaf, S. Estrada and J. Russo, Role of p53 in MCF-10F cell immortalization and chemically-induced neoplastic transformation, Int. J. Oncol. 7 (1995), 1289-1296.

[2] F. Basolo, J. Elliot, L. Tait and J. Russo, Transformation of human breast epithelial cells by c-Ha-ras oncogene, Mol. Carcinogen. 4 (1991), 25-35.

[3] G.M. Bokoch and C.J. Der, Emerging concepts in the Ras superfamily of GTP-binding proteins, FASEB J. 7 (1993), 750-759.

[4] G. Calaf and J. Russo, Transformation of human breast epithelial cells by chemical carcinogens, Carcinogenesis $\mathbf{1 4}$ (1993), 483-492.

[5] G. Calaf, P.L. Hang, M.V. Alvarado, S. Estrada and J. Russo, c-Ha-ras enhances the neoplastic transformation of human breast epithelial cells treated with chemical carcinogens, Int. J. Oncol. 6 (1995), 5-11.

[6] N. Denko, J. Stringer, M. Wani and P. Stambrook, Mitotic consequences of genomic instability induced by oncogenic Ha-ras, Som. Cell Mol. Genet. 21 (1995), 241-253.

[7] E.R. Fearon and B. Vogelstein, A genetic model for colorectal tumourigenesis, Cell 61 (1990), 759-767.

[8] B. Helpap, Nucleolar grading of breast cancer: Comparative studies on frequency and localization of nucleoli and histology stage, hormonal receptor status and lectin histochemistry, Virchows Arch. A: Pathol. Anat. 415 (1989), 501-508.

[9] T. Ichikawa, N. Kyprianou and J.T. Isaacs, Genetic instability and acquisition of metastatic ability by rat mammary cancer cells following v-Ha-ras oncogene transfection, Cancer Res. 50 (1990), 6349-6357.

[10] H.M.H. Kamel, J. Kirk and P.G. Toner, Ultrastrutural pathology of the nucleus, in: Pathology of the Nucleus, J.C.E. Underwood, ed., Curr. Opinion Pathol., Springer, Berlin, 1990, pp. 16-65.

[11] E.L. Lehmann, Nonparametrics: Statistic Methods Based on Ranks, Holden-Day, San Francisco, CA, 1973, pp. 457.

[12] M.L.S. Mello, Relocation of RNA metacromasy at mitosis, Acta Histochem. Cytochem. 28 (1995), 149-154.

[13] M.L.S. Mello and A.F. Chambers, Image analysis of Feulgen-stained transformed NIH/3T3 cells differing in p21 expression and ras-induced metastatic ability, Anal. Quant. Cytol. Histol. 16 (1994), 113-123.

[14] M.L.S. Mello, B.C. Vidal, W. Golembieski and J. Russo, Image analysis of Feulgen-stained NIH/3T3 cells transformed with DNA of 4-nitroquinoline 1-oxide-treated human breast epithelial cells, Biochem. Cell Biol. 70 (1992), 109-116.

[15] M.L.S. Mello, B.C. Vidal, M.M. Dantas and A.L.P. Monteiro, Discrimination of the nucleolus by a critical electrolyte concentration method, Acta Histochem. Cytochem. 26 (1993), 1-3.

[16] M.L.S. Mello, T.Y. Lin and J. Russo, Scanning microphotometry image analysis of Ha-ras-transformed human breast epithelial cells, Anal. Cell. Pathol. 7 (1994), 301-319.

[17] M.L.S. Mello, J. Russo and B.C. Vidal, Effect of the Ha-ras oncogene on chromatin supraorganization of benzo[a]pyrene-transformed human breast epithelial cells, Proc. Am. Assoc. Cancer Res. 39 (1998), 638. 
[18] K.J. Pienta, A.W. Partin and D.S. Coffey, Cancer as a disease of DNA organization and dynamic cell structure, Cancer Res. 49 (1989), 2525-2532.

[19] G.C. Prendergast and J.B. Gibbs, Pathways of the ras function: connections to the actin cytoskeleton, Adv. Cancer Res. 62 (1993), 19-64.

[20] H.G. Schwarzacher and F. Wachtler, The nucleolus, Anat. Embryol. 188 (1993), 515-536.

[21] H.D. Soule, T.M. Maloney, S.R. Wolman, W.D. Peterson, R. Brenz, C.M. McGrath, J. Russo, R.J. Pauley, R.F. Jones and S.C. Brooks, Isolation and characterization of a spontaneously immortalized human breast epithelial cell line, MCF-10, Cancer Res. 50 (1990), 6075-6086.

[22] Y. Tajima, H. Ishige and Y. Kondo, Morphometric studies for objective diagnosis of intraductal carcinoma of the breast, Acta Pathol. Jpn. 41 (1991), 604-609.

[23] P.J. van Diest, K.J. Risse, N.W. Schipper and J.P.A. Baak, Comparison of light microscopic grading and morphometric features in cytological breast cancer specimens, Path. Res. Pract. 185 (1989), 612-616.

[24] P.J. van Diest, J. Mouriquand, N.W. Schipper and J.P.A. Baak, Prognostic value of nucleolar morphometric variables in cytological breast cancer specimens, J. Clin. Pathol. 43 (1990), 157-159.

[25] B.C. Vidal, J. Russo and M.L.S. Mello, High performance cytometry of benzo[a]pyrene-transformed human breast epithelial cells, Proc. Am. Assoc. Cancer Res. 88 (1997), 1645.

[26] M.A. Wani, X. Xu and P.J. Stambrook, Increased methotrexate resistance and $d h f r$ gene amplification as a consequence of induced Ha-ras expression in NIH 3T3 cells, Cancer Res. 54 (1994), 2504-2508.

[27] Y. Wu, N. Barnabas, I.H. Russo, X. Yang and J. Russo, Microsatellite and loss of heterozygosity in chromosomes 9 and 16 in human breast epithelial cells transformed by carcinogens, Carcinogenesis 18 (1997), 1069-1074.

[28] P.-L. Zhang, Y.L. Chai, T.Y. Ho, G. Calaf and J. Russo, Allele loss and point mutation in codons 12 and 61 of the c-Ha-ras oncogene in carcinogen-transformed human breast epithelial cells, Mol. Carcinogen. 9 (1994), 46-56.

[29] P.-L. Zhang, Y.L. Chai, T.Y. Ho, G. Calaf and J. Russo, Activation of c-myc, c-neu and int-2 oncogenes in the transformation of the human breast epithelial cell line MCF-10F treated with chemical carcinogenesis in vitro, Int. J. Oncol. 6 (1995), 963-968. 


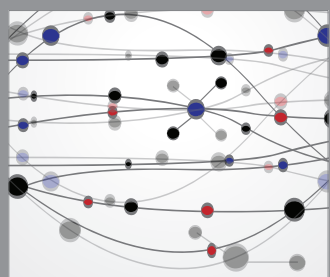

The Scientific World Journal
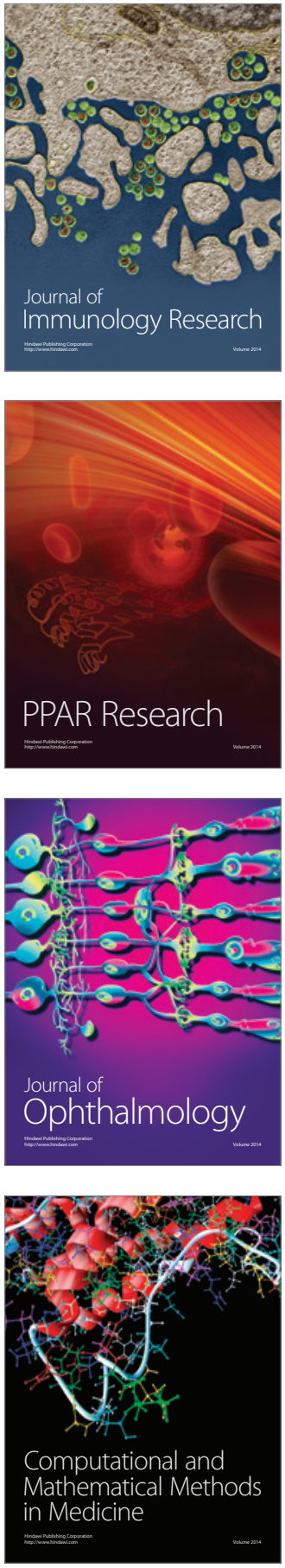

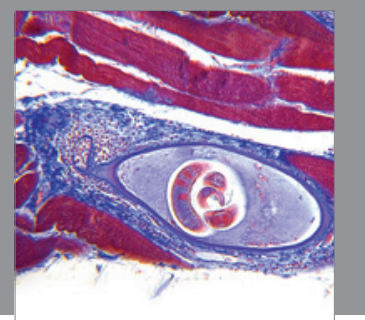

Gastroenterology

Research and Practice
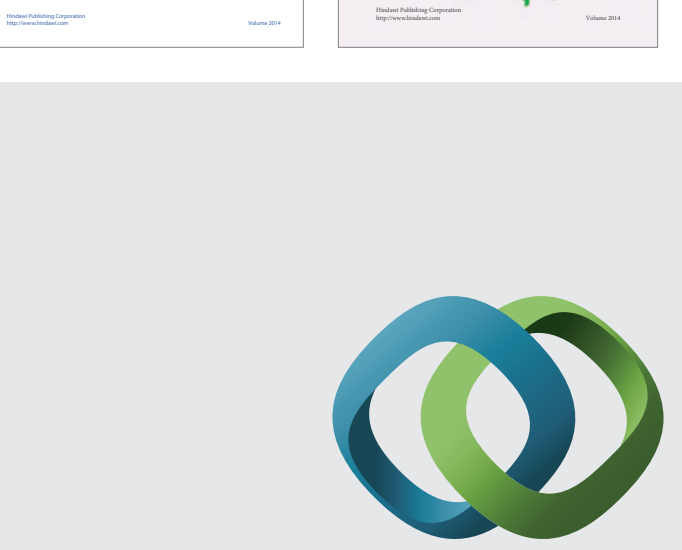

\section{Hindawi}

Submit your manuscripts at

http://www.hindawi.com
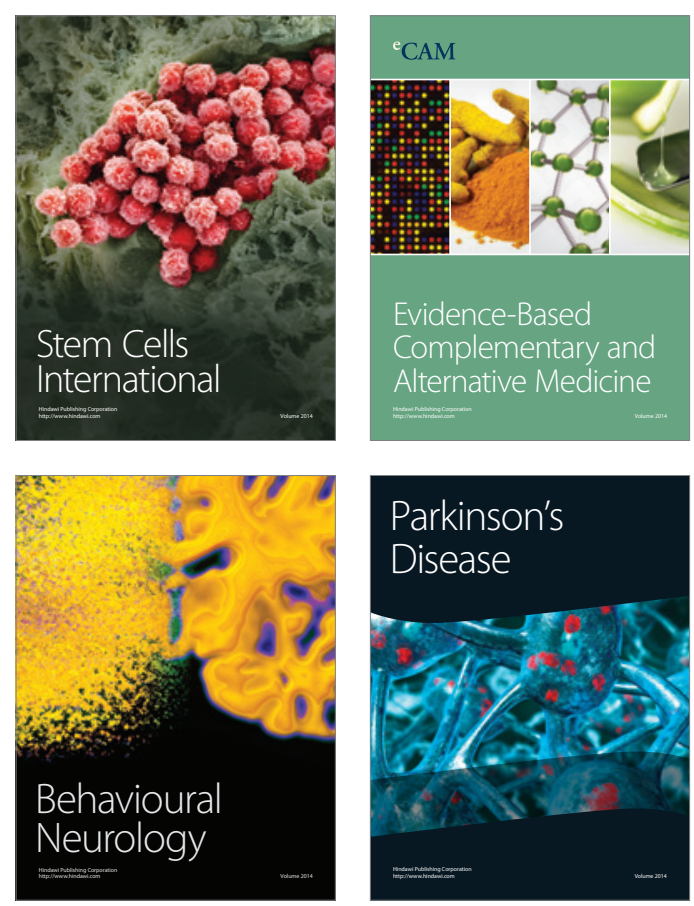

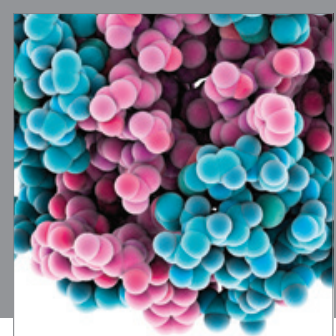

Journal of
Diabetes Research

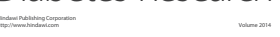

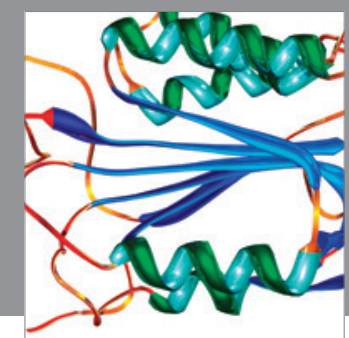

Disease Markers
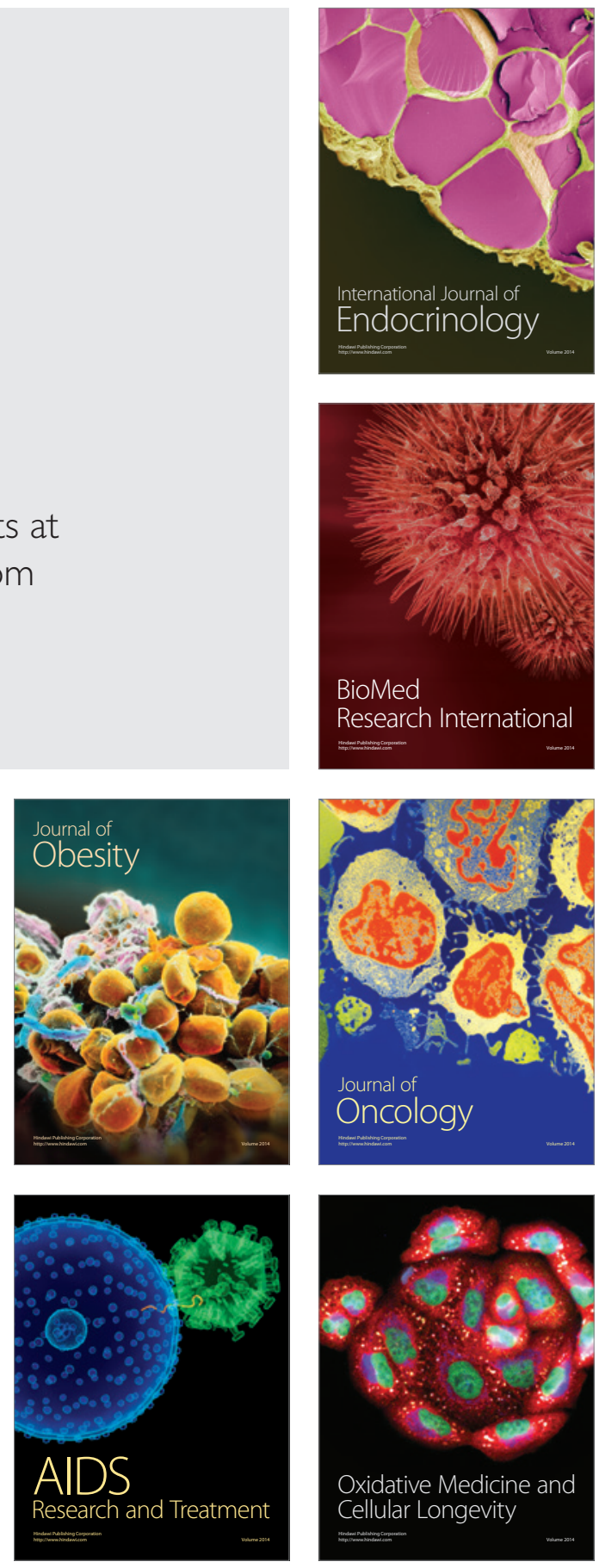